\title{
Analitik Hiyerarşi Süreci ve Promethee Tabanlı Kampüs İçi Erişim Lokasyonlarının Değerlendirilmesi: Manisa Celal Bayar Üniversitesi'nde Bir Uygulama
}

\author{
Muhammet Enes Akpınara, b, Kamil Koçak
}

Özet

Yer seçim problemi son yıllarda birçok farklı alanda dikkate alınan ve bu sebeple popüler karar verme problemlerdendir. Bu problemler çok sayıda kriterin dikkate alınması gerektiği için en uygun çok kriterli karar verme yöntemleri ile çözülebilen problem tiplerindendir. Bu çalışmada Manisa Celal Bayar Üniversitesi, Şehit Prof. Dr İlhan Varank kampüsünde bulunan bisiklet istasyonları için alternatif yer seçim çalışması yapılmıştır. Bir gerçek hayat uygulaması sunulan bu çalışmada bisiklet paylaşım istasyonlarının mevcut durumunun yetersiz olması sebebiyle öğrenci yoğunluğuna göre yeni alternatif bisiklet istasyonu yerlerinden en uygununu belirlemek öncelikli amaç olmuştur. Bu alternatif bisiklet istasyonlarını belirlemek için yoğunluk bölgelerinin olduğu dört farklı nokta belirlenmiştir. Bununla birlikte, en uygun alternatif istasyonun bulunabilmesi için farklı çok kriterli karar verme yöntemleri bir coğrafi bilgi sistemi (CBS) ile birleştirilmiştir. Analitik hiyerarşi süreci kriter ağırlıklarını elde etmek için uygulanmış ve PROMETHEE yöntemi ile alternatif istasyonların sıralaması yapılmıştır. Son olarak, hesaplanan veriler neticesinde en uygun alternatif istasyona karar verilmiştir.
Anahtar Kelimeler

Çok kriterli karar verme

PROMETHEE yöntemi

Coğrafi Bilgi Sistemi

Analitik hiyerarşi süreci

Makale Hakkında

Geliş Tarihi: 08.01.2021

Kabul Tarihi: 21.06.2021

Doi: $10.18026 /$ cbayarsos. 856520

\section{Analytical Hierarchy Process and PROMETHEE Based Evaluation of Campus Access Locations: An Application in Manisa Celal Bayar University}

\begin{abstract}
The location selection problem has been considered in many different areas in recent years and is, therefore, one of the most popular decision-making problems. These problems are among the types of problems that can be solved with the most appropriate multi-criteria decision-making methods since many criteria must be taken into account. In this study, an alternative site selection study has been adhered to for the bicycle stations in Manisa Celal Bayar University Sehit Prof. Dr. İlhan Varank Campus. The primary goal was to determine the most suitable new alternative places according to the student density due to the insufficient current situation of bike-sharing stations. In order to determine this alternative, four different points with intensity zones were considered as criteria. However, four alternative stations were determined and different multi-criteria decision-making methods were combined with a geographic information system (GIS). An analytical hierarchy process was applied to obtain the criterion weights and alternative stations were sorted by the PROMETHEE method. Finally, as a result of the calculated data, the most suitable alternative station was decided.
\end{abstract}

Keywords

Multi-criteria decision making PROMETHEE method

Geographic Information System Analytical Hierarchy Process

About Article

Received: 08.01.2021

Accepted: 21.06.2021

Doi: $10.18026 /$ cbayarsos. 856520

a İletişim Yazarı: enes.akpinar@cbu.edu.tr

b Arş.Gör. Dr., Manisa Celal Bayar Üniversitesi, Mühendislik Fakültesi, Endüstri Müh. Böl., Türkiye. ORCID: https://orcid.org/0000-0003-0328-6107 c Şube Müdürü, Dokuz Eylül Üniversitesi, Kütüphane ve Dokümantasyon Daire Bşk., İzmir, Türkiye. ORCID: https://orcid.org/0000-0002-8337-7019 


\section{Giriş}

Yer seçimi, kuruluşların hizmet veya satışını vermiş olduğu ürünlerin dağıtımı, üretimi, taşınması, depolanması veya teslimi için önemli bir karardır. Yer seçimi teoremlerinde kullanılan tesis terimi fabrika, okul, ticari-endüstriyel-kamu binaları olarak gösterilebilir. Yer seçimi kararları genellikle birden fazla alternatifin belirlenmesi, değerlendirilmesi ve seçilmesi ile sonuçlanır. Sosyal yaşam alanları, toplu konutlar, depolar, alışveriş merkezleri, hava alanları ve acil servis noktaları lokasyonları gibi yerleşim yerleri seçilen merkezler arasındadır (Healey ve Ilbery, 1990).

Akademide ve iş dünyasında yer seçimi problemleri, her geçen gün daha fazla kişi tarafından çalışılan problem haline gelmiştir. Bu problemler aynı zamanda farklı disiplinlerdeki araştırmacılar için birlikte çözülmesi gereken sorunlardır. Yer seçimi, birçok farklı yerleşim alternatifi, birden çok kriter ve birden çok aşamanın birlikte düşünülmesi ve bu şekilde dikkate alınması gereken bir süreçtir. Ayrıca, yer seçimi sırasında alınan nihai kararlar değişken ve dinamik bir ortamda verildiği için, beklenmeyen olaylar nedeniyle bazı kriterler değişebilmektedir. Karar verme aşamasında her bir alternatf yer ağırlığı oranında avantajlıdır ancak verilecek son karar için tüm kriterler ve alternatifler birlikte dikkate alınmalıdır (Jun, 2000).

Literatürde yer seçimi ile ilgili birçok çalışma bulunmaktadır. Analitik Hiyerarşi Süreci (AHS) yöntemini bulanık ortamda dikkate alan çalışmada bir yer seçimi uygulaması yapılmıştır ( $\mathrm{Wu}$ vd, 2009; Vahidnia 2009). Yer seçiminde kullanılan başka bir yöntem ise coğrafi bilgi sistemidir (Murad, 2007; Sharmin ve Neema, 2013; Rahimi vd, 2017). Delphi metodu Wu vd. (2007), Analitik Ağ Tasarımı (Sipahi ve Timor, 2010), çok amaçlı optimizasyon yaklaşımları (Zhang, 2016), ELECTRE-PROMETHEE (Velasquez ve Hester, 2013), MACBETCH (Dyer, 2005), bulanik AHS-TOPSIS (Choudhary ve Shankar, 2012), hedef programlama (Chang, 2015), yapay arı kolonisi algoritması ve yer çekimi arama algoritması (Kumar ve Srikanth, 2015), bulanık VIKOR (Mokhtarian vd, 2014), parçacık sürü optimizasyonu (Gang vd, 2015), genetik algoritma (Yang vd, 2007), yapay sinir ağları (Kayıkçı, 2010), bulanık ağırlıklı ortalama yöntemi (Mokhtarian, 2011), ağırlıklı toplam yaklaşımı (Kampf vd, 2011), geri teori (Ka, 2011), AHS ve matematiksel model (Hong ve Xiaohua, 2011) ve karma tamsayılı programlama (Correia ve Antunes, 2012) yer seçiminde kullanılan diğer yaklaşımlardır.

Yer seçimi problemleri literatüründe yapılan araştırmada öğrenci ulaşım alternatiflerin değerlendirilmesi aşamasında PROMETHEE yönteminin bu alanda daha önce uygulanmadığı görülmüştür. Bu yöntem gerek alternatiflerin arasında bir sıralama vermesi gerekse de ideal çözüme göre hesaplama yapması açısından diğer çok kriterli karar verme yöntemlerinden ayrışmaktadır. PROMETHEE yönteminin üniversite kampüs içi uygulamalarda da kullanılmamış olması literatürde bir boşluk olduğu anlamına gelmektedir. Bu boşluğu doldurabilmek için bu çalışmada PROMETHEE yöntemi dikkate alınarak, Manisa Celal Bayar Üniversitesi (MCBU)'nde öğrencilerin kampüs için ulaşımını kolaylaştırmak için bir çalışma yapılmıştır. Yapılan çalışmada öğrencilerin kullanımı için farklı konumlarda bulunan bisiklet istasyonları değerlendirilmiş ve alternatif yeni istasyonlar önerilmiştir. Çalışmanın gerçek hayat uygulaması olması bakımından yeni yapılacak çalışmalara yol gösterici olması beklenmektedir. 
Çalışmanın geri kalan kısmında öncelikle kullanılacak yönteme değinilmiştir. Sonrasında problem tanımlanmış ve çözümü aşamalı olarak aktarılmıştır. Son olarak çalışmanın sonuçları ve gelecekte yapılabilecek çalışmalara değinilmiştir.

\section{Materyal ve Yöntem}

Bu bölümde çalışmada problemin çözümü için kullanılan yöntemler hakkında bilgi verilmiştir. İlerleyen bölümde ise bu yöntemlerin problem üzerindeki uygulamasına değinilmiştir.

\section{PROMETHEE Yöntemi}

$\mathrm{Bu}$ çalışmada çok kriterli karar verme probleminin çözümünde en etkili ve kolay uygulanan yöntemlerden biri olan PROMETHEE (The Preference Raking Organization METHod for Enrichment Evaluation) yönteminden faydalanılmıştır. Yöntem, karar verme problemine esas olan alternatifleri, belirlenen tercih fonksiyonuna dayanarak değerlendirmekte ve alternatifleri ikili karşılaştırmalarla kısmi ve tam önceliklendirmektedir.

PROMETHEE yönteminde sonlu sayıda alternatif üzerinde hem kısmi siralama (PROMETHEE I) hem de tam sıralama (PROMETHEE II) yapılabilmektedir. Yöntem, karar verme probleminde karara esas teşkil edecek alternatiflerin sıralamasını sağlamaktadır. Yöntem şu şekilde uygulanmaktadır (Şenkayas ve Hekimoğlu, 2013: 68-73):

Adım 1: Karar verici, karar noktalarını ve değerlendirme faktörleri tanımlar. Ardından değerlendirme faktörlerinin önem ağırlığını belirleyerek veri kümesi oluşturur.

Adım 2: Belirlenen değerlendirme faktörlerinin yapısını ve iç ilişkisini göstermek için tercih fonksiyonları belirlenir.

Adım 3: Belirlenen tercih fonksiyonları dikkate alınarak her bir değerlendirme faktörü için karar noktalarının ikili karşılaştırmaları yapılır ve ortak tercih fonksiyonları belirlenir.

Adım 4: Ortak tercih fonksiyonları kullanılarak karşılaştırılan karar noktalarına ilişkin tercih endeksleri belirlenir.

Adım 5: Karar noktaları için pozitif ve negatif üstünlük değerleri belirlenir.

Adım 6: PROMETHEE I ile kısmi sıralama belirlenir.

Adım 7: PROMETHEE II ile karar noktalarının tam sıralaması belirlenir.

\section{Analitik Hiyerarşi Süreci (AHP)}

Saaty tarafından geliştirilen AHP tekniği, karmaşık karar problemlerini analiz eden ve çözen pratik bir ÇKKV tekniğidir (Saaty, 1980). Kriter ağırlıklarını veya öncelikleri belirlemek ve nicel-nitel değerlendirmelere bağlı olarak alternatifleri sıralamak için kullanılabilir. AHP yalnızca kriter ağırlıklarını veya öncelikleri belirlemek için uygulanabilir ve kriter ağırlıkları gerektiren diğer ÇKKV teknikleri için bir destek görevi görür.

AHP yönteminin başlıca avantajları şunlardır (Ishizaka ve Labib, 2009):

a. Üst düzeylerdeki öncelikteki olası değişikliklerin, alt düzeylerdeki kriterlerin önceliğini nasıl etkilediğini göstermektedir. 
b. Hiyerarşi içindeki değişikliklere ve buna yapılan eklemelere ilişkin kararlı ve esnektir.

c. AHP kullanılarak elde edilen ağırlık katsayılarının değerleri, ağırlık katsayılarının hesaplanmasında bir tutarlılık oranının dikkate alınması nedeniyle güvenilirdir.

$\mathrm{Bu}$ çalışmada, bisiklet paylaşım istasyonu kriterleri için AHP tekniği ile ağırlıklar hesaplanmıştır. Tekniği genişletmediğimiz ve kapsamlı açıklamalar çeşitli makalelerde kolayca bulunduğu için AHP yönteminin detayları bu çalışmada açıklanmamıştır (Subramanian ve Ramanathan, 2012; Chemweno vd., 2015; Kabak vd., 2016).

\section{Coğrafi Bilgi Sistemi (CBS)}

Coğrafi bilgi sistemleri, Dünya yüzeyindeki konumlarla ilgili verileri yakalamak, depolamak, analiz etmek ve görüntülemek için tasarlanmıştır. Şekil 1'de gösterildiği gibi, CBS, tek bir harita üzerinde birden çok bilgi katmanının görüntülenmesini sağlar. CBS'ne bilgi girişi, veri yakalama olarak bilinir. Uydu görüntüleri veya diğer yazılım tarafından oluşturulan veriler gibi halihazırda dijital formda olan veriler, CBS'ne kolayca yüklenir (Lepuschitz, 2015).

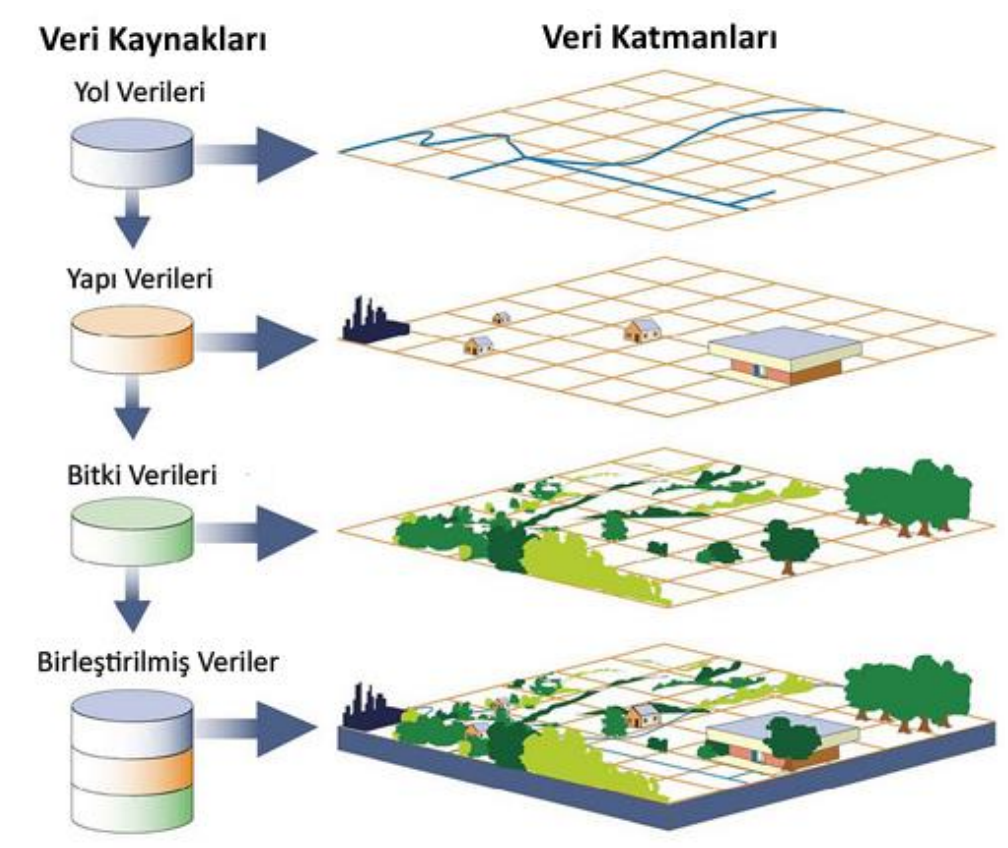

Şekil 1. Coğrafi bilgi sistemi katmanları (Lepuschitz, 2015).

Her veri türü için ayrı bir katman oluşturulur. Örneğin, bir katman nüfus yoğunluğunu gösterir, ikinci bir katman bisiklet hattı verilerini gösterir ve üçüncüsü yol verilerini gösterir. Katmanlar, tasvir ettikleri nesnelere göre şekil ve bilgi açısından farklılık gösterebilir. Ayrıca, nesnelerin şekilleri vektör verileri olabilir (Goodchild, 2015).

$\mathrm{Bu}$ çalışmada, bisiklet istasyonlarının ve kampüs yerleşkesinin detaylarını elde etmek için ArcGIS yazılımı kullanılmıştır. Bu yazılım, kullanıcıların belirlediği ihtiyaçlara göre mekansal bilgi ve özellikleri metin veya görüntü açısından doğru ve kapsamlı bir şekilde kullanıcılara ulaştırabilen ticari bir CBS yazılım ürünüdür (Cheng vd., 2013). 


\section{Bulgular}

$\mathrm{Bu}$ bölümde problemin tanımı ve çözümüne ilişkin kapsamlı bilgi verilmiştir. Çok kriterli karar verme yöntemlerinden olan AHP ve PROMETHEE yönteminin probleme uygulanması ve sonuçları da alt başlıklar halinde verilmiştir.

\section{Problemin Tanımı}

Manisa Türkiye'nin batısında bulunan ve üniversitesi her geçen yıl daha fazla talep gören bir konumdadır. Manisa'da tek üniversite olan MCBU bünyesinde farklı kampüslerde farklı sayıda öğrenciye eğitim vermektedir. Bu çalışmada, bu kampüslerden Şehit Prof. Dr. İlhan Varank yerleşlesinde bulunan mevcut bisiklet lokasyonlarının değerlendirilmesi ve alternatif yerler önerilmesi üzerine bir probleme getirilen önerinin detayları verilmiştir. Manisa ve kampüsün konumu CBS olarak Şekil 2'de verilmiştir.

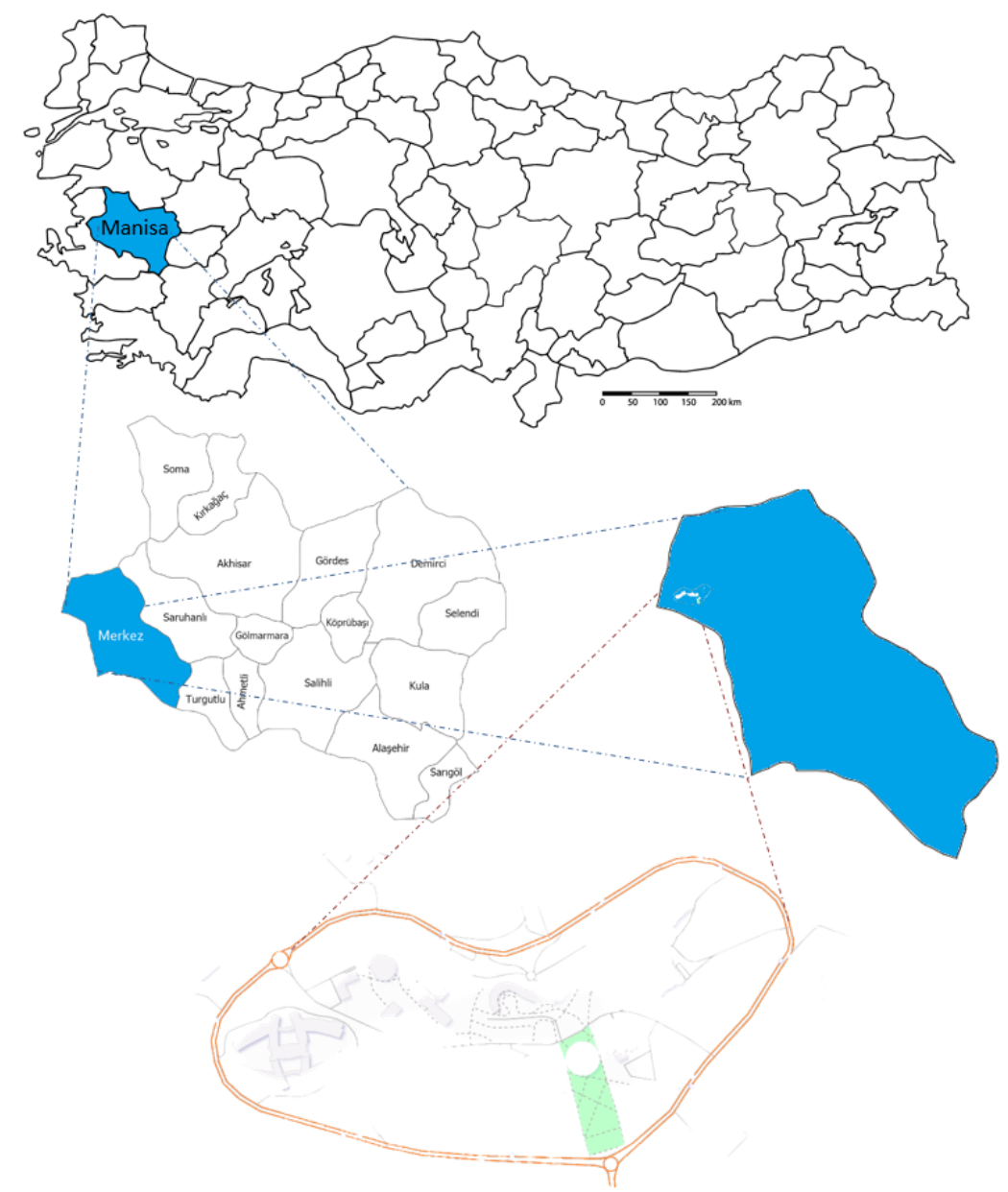

Şekil 2. MCBÜ kampüsünün konumu

MCBÜ Şehit Prof. Dr. İlhan Varank kampüsünde üç farklı lokasyonda öğrencilerin kullanımı için bisiklet istasyonları bulunmaktadır. Öğrenciler bu bisikletleri öğrenci kartlarını kullanarak kampüs içinde istedikleri şekilde ulaşımlarını sağlayabilmektedirler. Bisiklet istasyonlarının konumlarının öğrenci yoğunluk merkezlerine olan mesafesinin oldukça uzak olması, bu istasyonların verimli kullanılmamasına sebep olmaktadır. Buradan hareketle bu çalışmada, mevcut istasyonlara alternatif yeni istasyonlar çok kriterli karar verme yöntemleri kullanılarak önerilmiştir. 


\section{Kriterlerin Belirlenmesi}

Öğrencilerin mevcut bisiklet istasyonlarından verim alamaması üzerine yapılan bu çalışmada, öğrencilerin daha çok zaman geçirdikleri yerler tespit edilerek bu bölgelere yakın olması açısından kriterler Şekil 3'teki gibi belirlenmiştir.

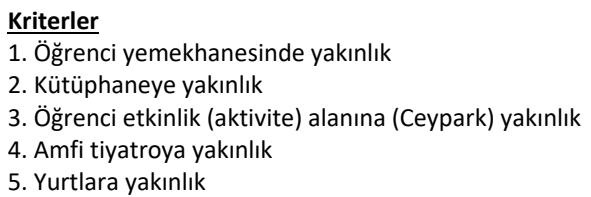

1. Öğrenci yemekhanesinde yakınlık

2. Kütüphaneye yakınlık

3. Öğrenci etkinlik (aktivite) alanına (Ceypark) yakınlık

4. Amfi tiyatroya yakınlık

5. Yurtlara yakınlık

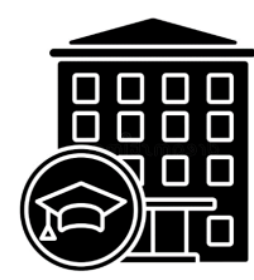

Kriter 5
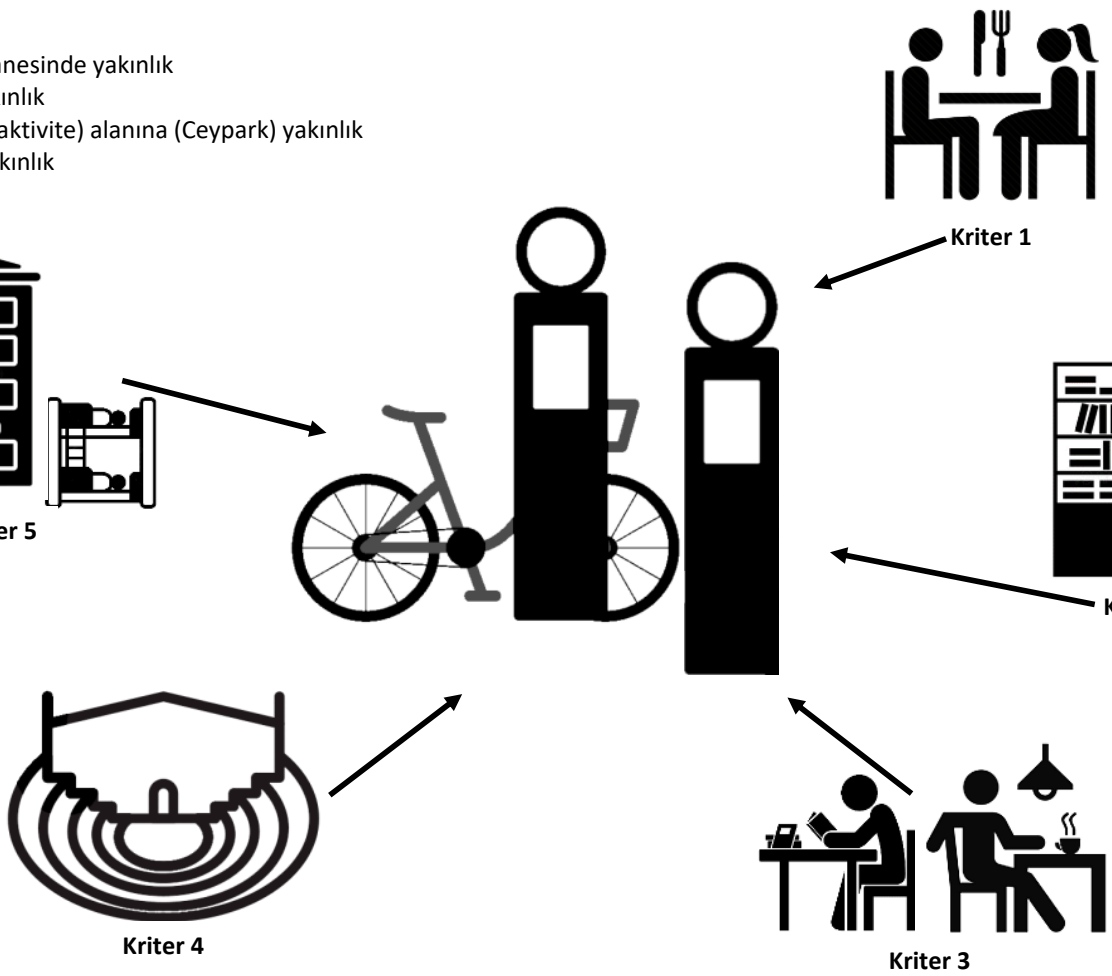

Şekil 3. Alternatif bisiklet istasyonu seçim kriterleri

\section{Alternatiflerin belirlenmesi}

Alternatif istasyonları belirleme aşamasına geçmeden önce mevcut istasyonların konumları Google Map üzerinden enlem ve boylam (koordinat) bilgileri Tablo 1'de verilmiştir.

Tablo 1. Mevcut istasyonların konumu:

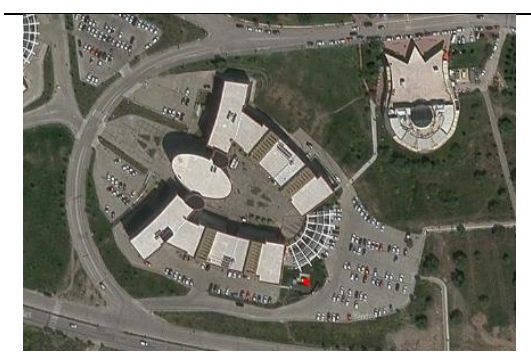

Enlem : 38²0'32.69"K

Boylam : $27^{\circ} 18^{\prime} 21.09^{\prime \prime D}$

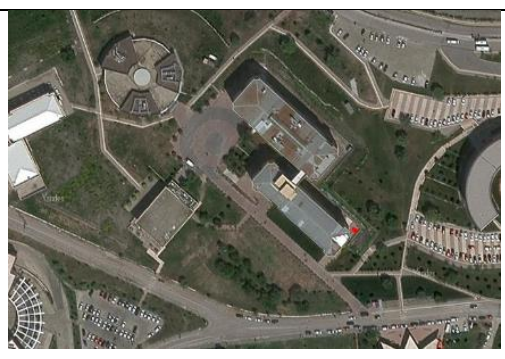

Enlem: 3840'39.60"K

Boylam: $27^{\circ} 18^{\prime} 22.43^{\prime \prime} \mathrm{D}$

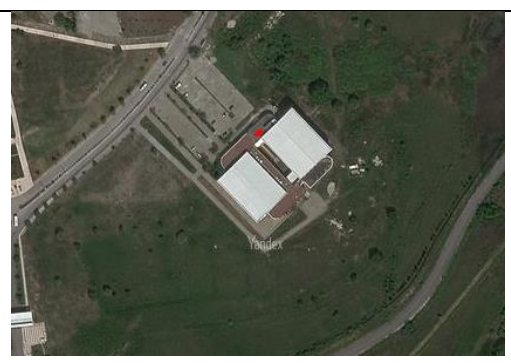

Enlem : $38^{\circ} 40^{\prime} 32.88^{\prime \prime} \mathrm{K}$

Boylam: $27^{\circ} 18^{\prime} 43.49^{\prime \prime} \mathrm{D}$

Mevcut istasyonların konumunun ArcGIS yazılımı üzerindeki görüntüsü ve kampüsün görüntüsü Şekil 4 ve Şekil 5'te verilmiştir. 


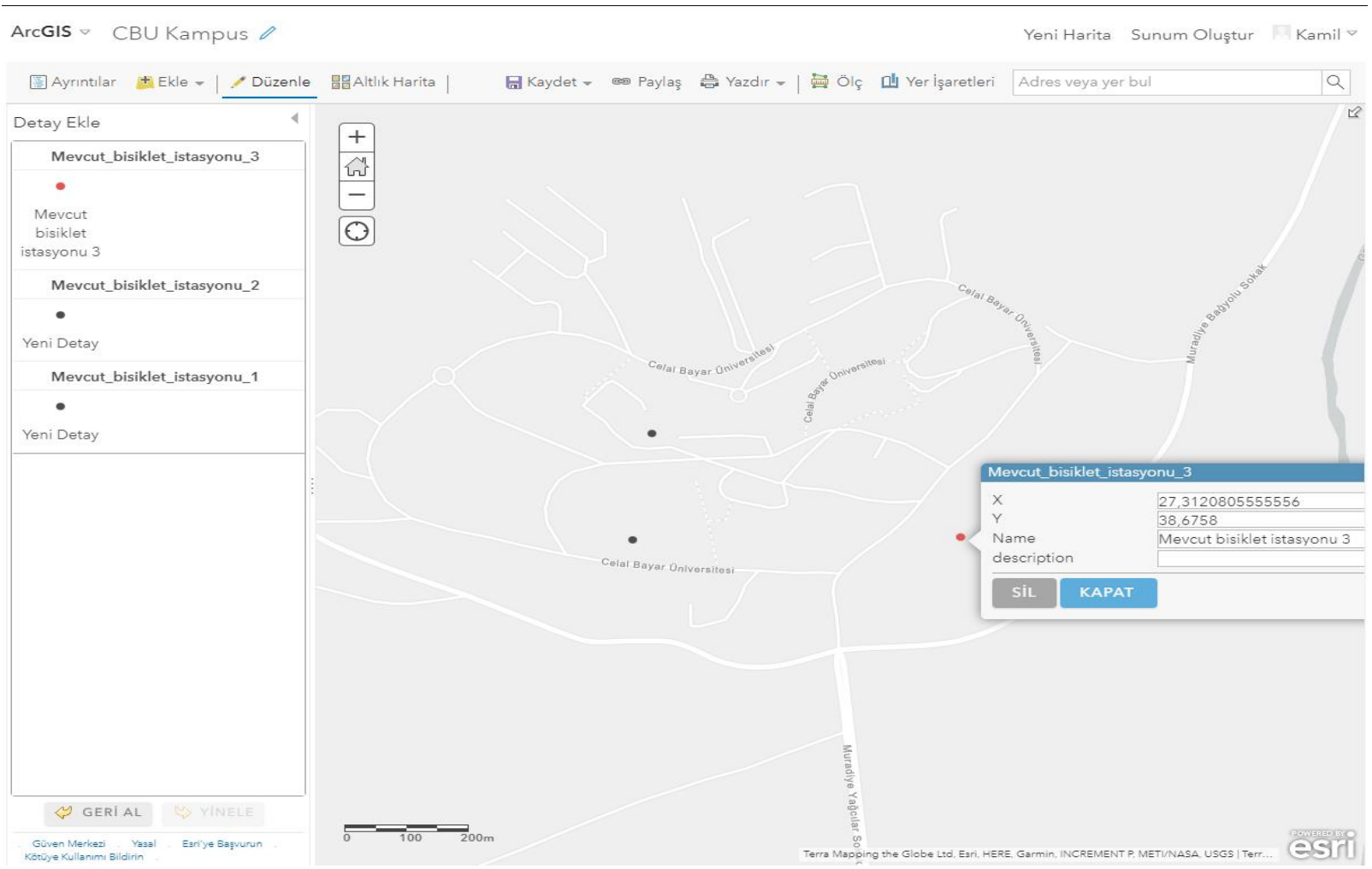

Şekil 4. Mevcut istasyonların ArcGIS görüntüsü

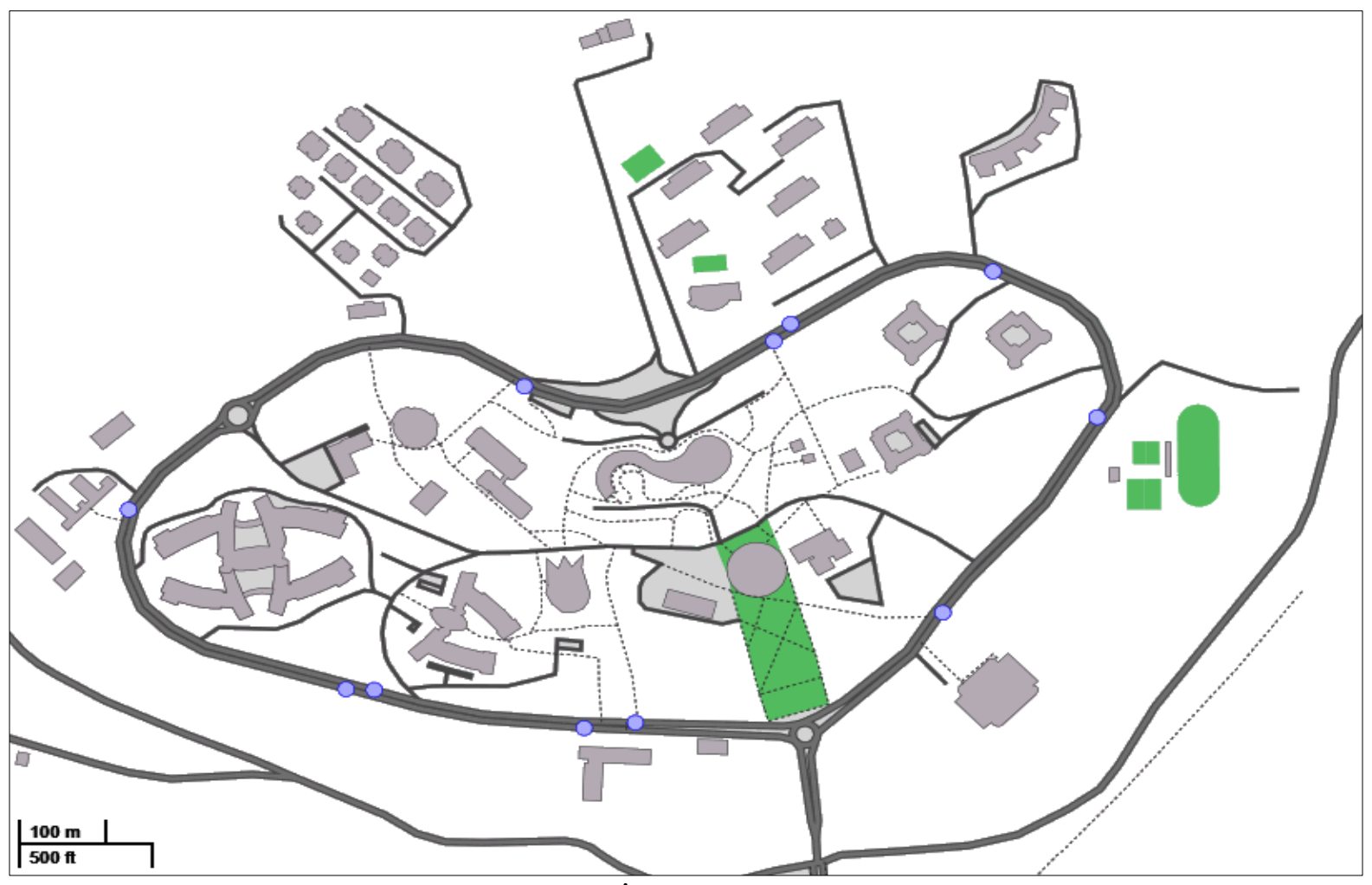

Şekil 5. Şehit Prof. Dr. İlhan Varank ArcGIS görüntüsü 
Mevcut istasyonlara alternatif olarak belirlenen istasyonlar Şekil 6'da verilmiştir. Bu şekilde mevcut istasyonlar, alternatif istasyonlar ve kriterlerin konum olarak yerleri detaylı bir şekilde gösterilmektedir. Çalışmanın amacı belirlenen beş kriteri en iyi düzeyde karşılayan dört farklı bisiklet istasyonundan hangisinin en uygun olduğuna karar vermektir.

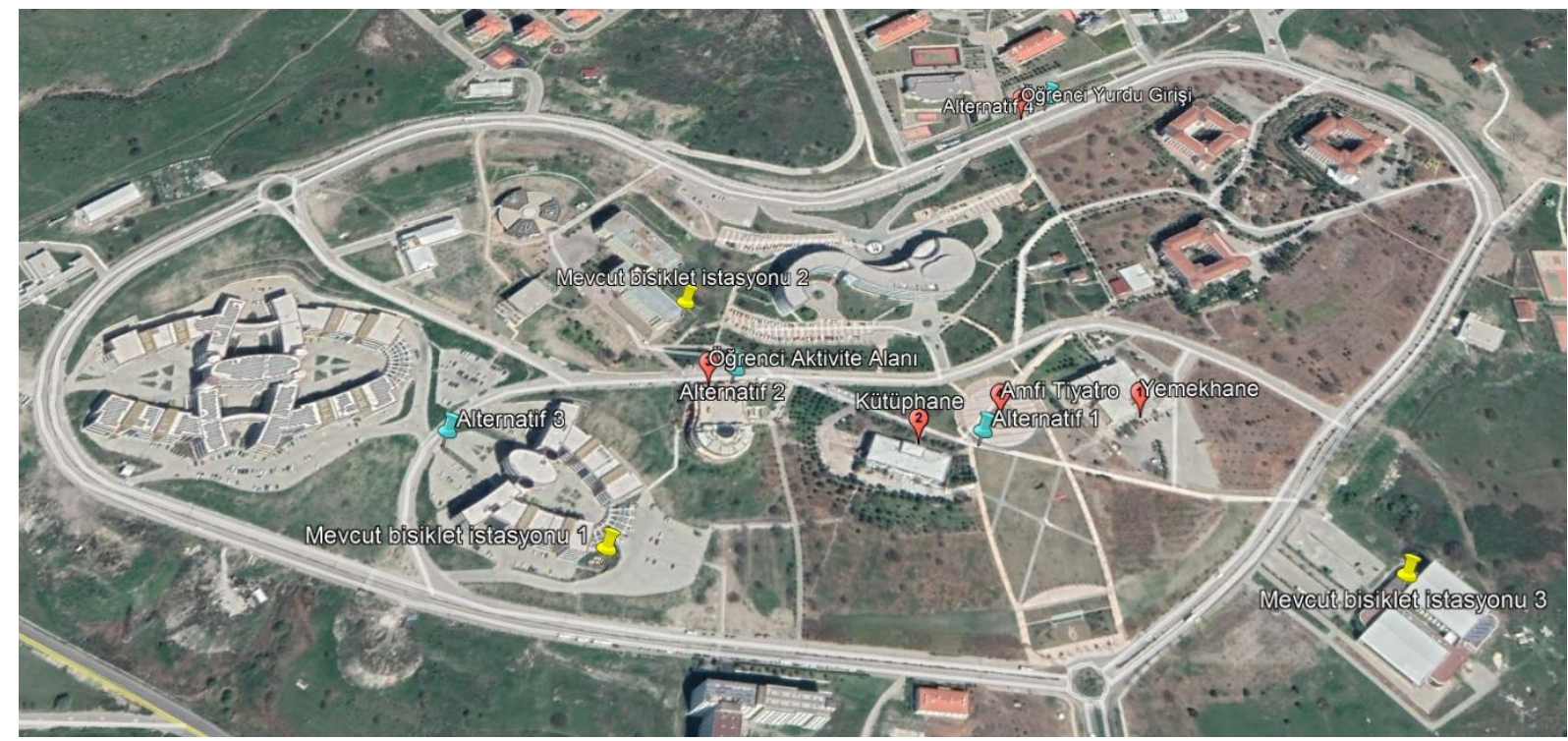

Şekil 6. Mevcut ve alternatif istasyonların kampüs içindeki konumu

En uygun alternatif bisiklet istasyonuna karar vermek için öncelikle belirlenmiş beş kriterin ağırlıklarının belirlenmesi gerekmektedir. Bunun için ilk olarak AHP yöntemi ile ağırlık belirlenmiştir. Ağırlıklar belirlenirken ilgili departmanda çalışan üç uzmanın fikri alınmıştır. Sonrasında her bir kriterin kendi aralarındaki kıyaslama için uzmanların verdiği değerlerin ortalaması alınmıştır. Tablo 2 uzmanların kriterleri değerlendirmesi aşamasında kullandığı ölçeği göstermektedir. Bu ölçek doğrultusunda her bir kriterin ortalaması alınarak elde edilen başlangıç matrisi Tablo 3'te verilmiştir. AHP adımları uygulanarak elde edilen kriter ağırlıklarının nihai sonucu Tablo 4'te verilmiştir.

Tablo 2. Analitik Hiyerarşi Süreci Ölçek Matrisi (Saaty, 1980)

\begin{tabular}{cc}
\hline Önem Değerleri & Değer Tanımları \\
\hline 1 & Eşit önemde \\
5 & Oiraz daha önemli (Az üstünlük) \\
7 & Çok önemli (Çok üstünlük) \\
9 & Son derece önemli (Kesin üstünlük) \\
$2,4,6$ ve 8 & Ara değerler (Uzlaşma değerleri) \\
\hline
\end{tabular}


Tablo 3. Kriterler arası önem değeri başlangıç matrisi

\begin{tabular}{lccccc}
\hline \multicolumn{1}{c}{ Kriterler } & K1 & K2 & K3 & K4 & K5 \\
\hline K1) Öğrenci Yemekhanesi'ne Yakınlık & 1 & $1 / 7$ & 3 & 5 & 3 \\
K2) Kütüphaneye Yakınlık & 7 & 1 & 7 & 7 & 7 \\
K3) Öğrenci Etkinlik Alanı'na Yakınlık & $1 / 3$ & $1 / 7$ & 1 & 3 & $1 / 5$ \\
K4) Amfi Tiyatro'ya Yakınlık & $1 / 5$ & $1 / 7$ & $1 / 3$ & 1 & $1 / 5$ \\
K5) Yurtlar'a Yakınlık & $1 / 3$ & $1 / 7$ & 5 & 5 & 1 \\
\hline
\end{tabular}

Tablo 4. AHP yöntemi ile kriter ağırlıklarının belirlenmesi

\begin{tabular}{lc}
\hline Kriterler & Ağırlık \\
\hline K1) Öğrenci Yemekhanesi'ne Yakınlık & 0,1777 \\
K2) Kütüphaneye Yakınlık & 0,5604 \\
K3) Öğrenci Etkinlik Alanı'na Yakınlık & 0,0700 \\
K4) Amfi Tiyatro'ya Yakınlık & 0,0398 \\
K5) Yurtlar'a Yakınlık & 0,1521 \\
\hline
\end{tabular}

Kriter ağırlıkları ile PROMETHEE sonuçlarını elde etmek için "Visual PROMETHEE" paket programı kullanılmıştır. Kullanılan bu yazılım ile PROMETHEE I ve PROMETHEE II sıralamaları hesaplanabilmektedir. PROMETHEE hesaplaması için kullanılan programda başlanıç matrisi verilmiş ve sonuçlar Şekil 7'de gösterilmiştir. İdeal çözüme ilişkin değerler ise Şekil 8'de belirtilmiştir. PROMETHEE I ve PROMETHEE II ile yapılan hesaplamaların sonuçları ise Şekil 9 ve Şekil 10'da verilmiştir.

Yapılan hesaplamalar sonucunda Şekil 9'de görüldüğü üzere kısmi sıralama açısından alternatif 1 en iyi alternatif olmuştur. Alternatif 2, alternatif 4 ve alternatif 3 sirasiyla en iyi alternatiften en kötü alternatife doğru sıralamayı göstermektedir.

Şekil 10'da ise tam sıralama sonucu verilmiştir ve bu sonuca göre de alternatif 1 en iyi alternatif bisiklet istasyonu olarak seçilmiştir. Kısmi sıralamada olduğu gibi alternatif 2, alternatif 4 ve alternatif 3 sonraki istasyonlardır. 


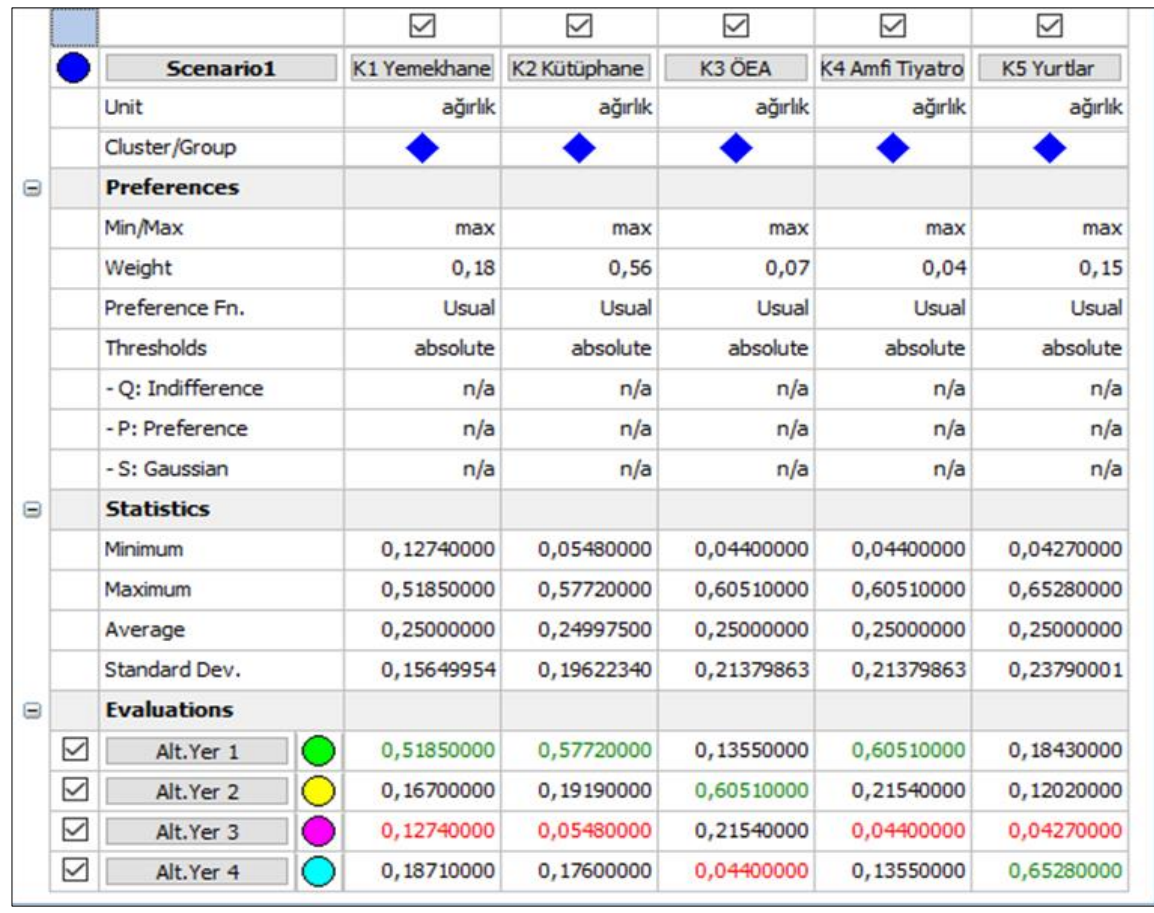

Şekil 7. Visual PROMETHEE başlangıç çözümü

\begin{tabular}{|c|c|c|c|c|}
\hline Rank & & Phi & Phit & Phi- \\
\hline 1 & Alt.Yer 1 & 0,8053 & 0,9026 & 0,0974 \\
\hline 2 & Alt.Yer 2 & 0,1601 & 0,5801 & 0,4199 \\
\hline 3 & Alt.Yer 4 & $-0,0587$ & 0,4706 & 0,5294 \\
\hline 4 & Alt.Yer 3 & $-0,9067$ & 0,0467 & 0,9533 \\
\hline
\end{tabular}

Şekil 8. PROMETHEE ideal çözüm değerleri

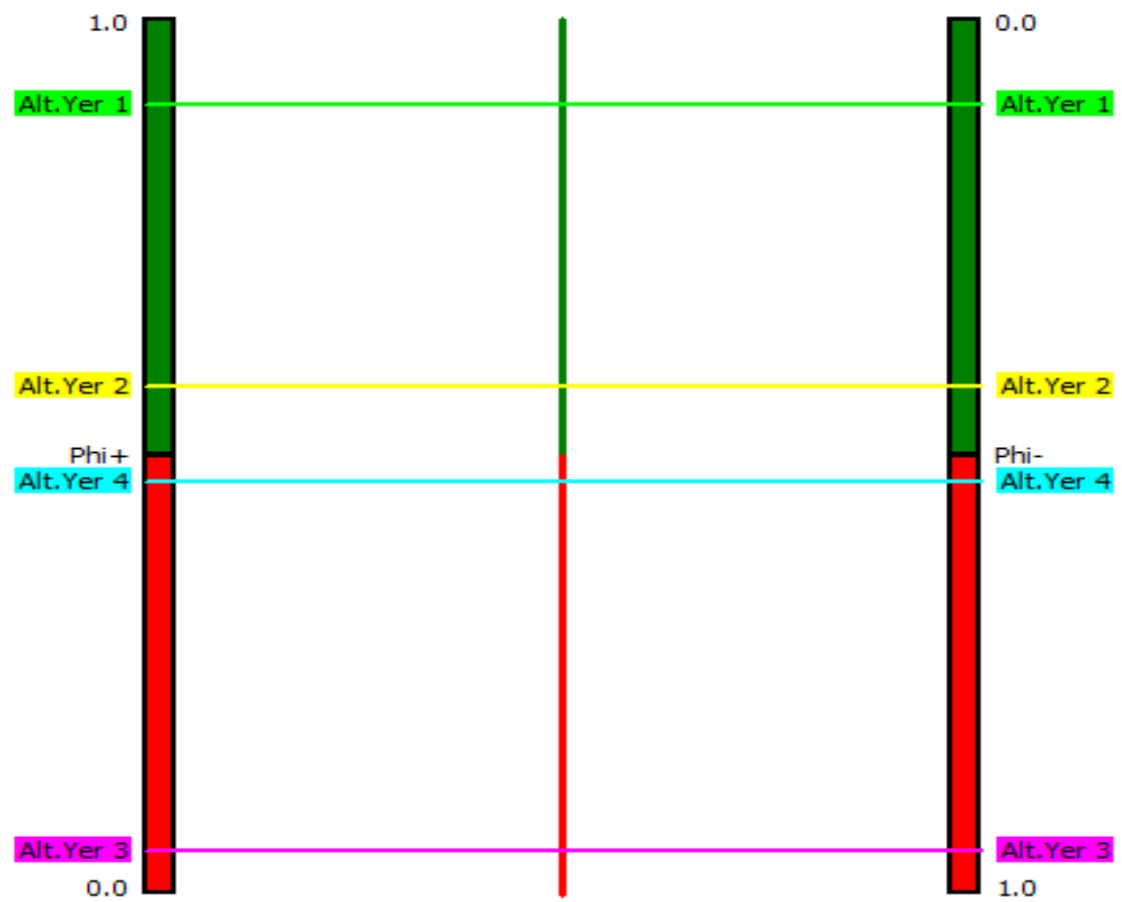

Şekil 9. PROMETHEE I ile kısmi sıralama 


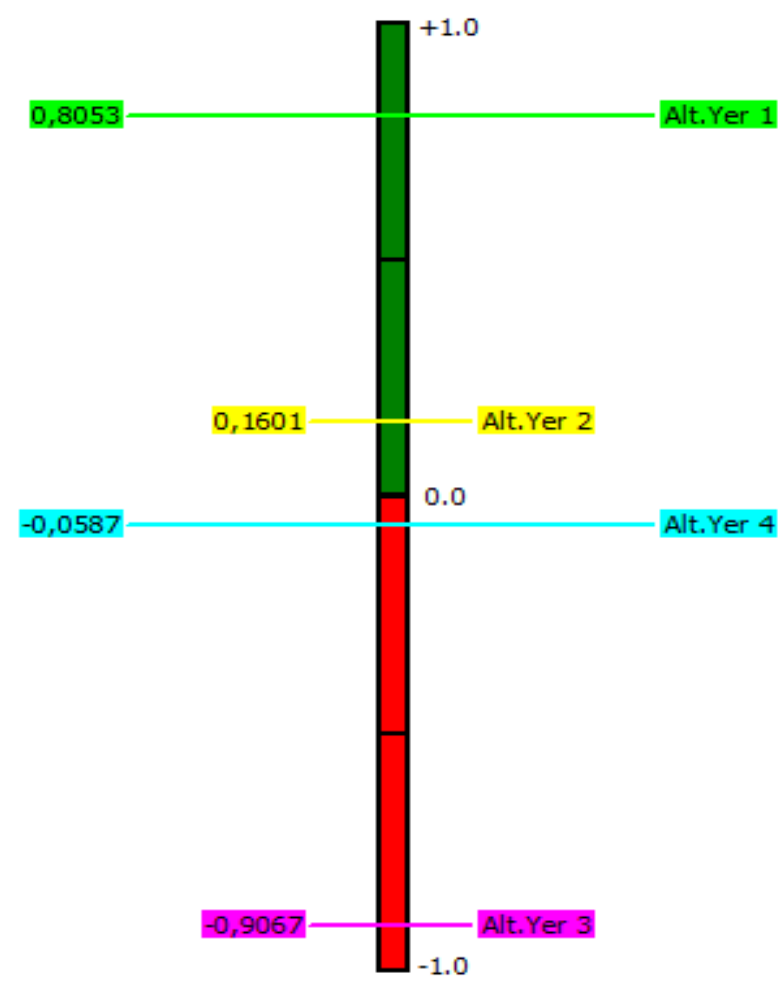

Şekil 10. PROMETHEE II ile tam sıralama

$\mathrm{Bu}$ bölümde yapılan AHP yöntemiyle öncelikle kriter ağırlıklarına karar verilmiştir. Sonrasında PROMETHEE yöntemi ile alternatiflerin sıralamasını belirlemek için bir yazılım kullanılmış ve sonuçlar elde edilmiştir. Mevcut üç bisiklet istasyonuna ilave olarak alternatif 1 istasyonuna yeni bir bisiklet istasyonu açılması gerekmektedir.

\section{Tartışma ve Sonuç}

Yer seçim problemleri özellikle karar verme problemlerinde çok sıklıkla kullanılan problem çeşitlerinden biridir. Yer seçimi, karar vericinin birçok alternatif içerisinden belirli kriterleri dikkate alarak en uygun alternatifin seçilmesi olarak da tanımlanabilir. Bu problem çeşitleri birçok farklı problemi içermekle birlikte özellikle gerçek hayat uygulamaları açısından kısıtlıdır. Yer seçimi problemlerinde bir gerçek hayat uygulaması olarak bu çalışmada bir üniversite için alternatif bisiklet istasyonları yer seçimi dikkate alınmıştır.

Kampüs içi ulaşımda günümüz artan problemlerinden biridir. Öğrencilerin kampüs içinde istedikleri noktalar arasında dolaşmak bazı durumlarda uzun süreler alabilmektedir. MCBU kampüsünde bulunan bisiklet istasyonları dikkate alınarak yapılan bu çalışmada mevcut istasyonlara ek olarak yeni bir istasyon önerilmiştir. Bu öneri için öncelikle ihtiyaç duyulan kriterler belirlenmiş ve sonrasında alternatif noktalar belirlenen çok kriterli karar verme yöntemlerinden AHP ve PROMETHEE ile problem çözülmüştür. Çalışmada kullanılan kriter veya alternatif lokasyonların sayısı çalışmanın kısıtları olarak belirtilebilir. Ayrıca kullanıla yöntemlerin kriterler arasındaki etkileşimi dikkate almaması da çalışmanın bir başka kisitidir.

İlerleyen çalışmalarda bisiklet istasyonlarına ek olarak elektrikli bisiklet olarak da adlandırılan ve şehir içi ulaşımda dahi kullanılan araçlar için farklı çalışmalar yapılabilir. Bu 
çalışmalar TOPSIS, VIKOR, ANP veya bulanık ortamda modelleme yapılarak literatüre farklı katk1lar da sunulabilir.

\section{Teşekkür ve Bilgilendirme}

Çalışmada verdikleri destek için Manisa Celal Bayar Üniversitesi Sağlık, Kültür ve Spor Dairesi çalışanlarına teşekkür ediyoruz.

\section{Kaynakça}

Chemweno, P., Pintelon, L., Van Horenbeek, A. \& Muchiri, P. (2015). Development of a risk assessment selection methodology for asset maintenance decision making: an analytic network process approach. Int. J. Prod. Econ. 170 (Part B), 663-676

Chang, C. T. (2015). Multi-choice goal programming model for the optimal location of renewable energy facilities. Renewable and Sustainable Energy Reviews, 41, 379-389.

Cheng, Y., Zhang, J. \& Peng, J., (2013). ArcGIS-based evaluation of geo-hazards at yaozhou county, shaanxi, China. J. Rock Mech. Geotech. Eng. 5, 330e334.

Choudhary, D. ve Shankar, R. (2012). An STEEP-fuzzy AHP-TOPSIS framework for evaluation and selection of thermal power plant location: A case study from India. Energy, 42, 510-521 doi:10.1016/j.energy.2012.03.010.

Correia, G. H. A. ve Antunes, A. P. (2012). Optimization approach to depot location and trip selection in one-way carsharing systems. Transportation Research Part E, 48 233-247.

Dyer J. S. (2005). Multiattribute Utility Theory. In: Greco S, Ehrgott M, Figueira J, editors. Multiple criteria decision Analysis: state of the art surveys. New York: Springer;p. 265-92 .

Gang, J., Tu, Y., Lev, B., Xu, J., Shen, W. ve Yao, L. (2015). A multi-objective bi-level location planning problem for stone industrial parks. Computers \&OperationsResearch, 56, 8-21.

Goodchild, M. F. (2015). In: Geographic Information Systems, International Encyclopedia of the Social \& Behavioral Sciences, second ed., pp. 58-63.

Healey, M. \& Ilbery, B. (1990). Location and Change: Perspectives on Economic Geography. Oxford University Press.

Hong, L. ve Xiaohua, Z. (2011). Study on location selection of multi-objective emergency logistics center based on AHP. Procedia Engineering, 15, 2128 - 2132 doi: 10.1016/S1005-8885(13)60110-7.

Ishizaka, A. \& Labib, A. (2009). Analytic hierarchy process and expert choice: benefits and limitations. OR Insight 22 (4), 201-220.

Jun, C. (2000). Design of an intelligent geographic information system for multi-criteria site analysis. URISA Journal, 12, 5-17.

Ka, B. (2011). Application of Fuzzy AHP and ELECTRE to China Dry Port Location Selection. The Asian Journal of Shipping and Logistics, 27, 331-354.

Kabak, M., Dagdeviren, M., Burmaoglu, S. (2016). A hybrid SWOT-FANP model for energy policy making in Turkey. Energy Sources B Energy Econ. Plann. 11 (6), 487-495.

Kampf, R., Prusa, P. ve Savage, C. (2011) Systematic location of the public logistic centres in Czech Republic, Transport, 26, 425-432 doi:10.3846/16484142.2011.635424.

Kayikci, Y. (2010). A conceptual model for intermodal freight logistics centre location decisions. Procedia Social and Behavioral Sciences, 2, 6297-6311. 
Kumar, B. V. ve Srikanth, N. V. (2015). Optimal location and sizing of Unified Power Flow Controller (UPFC) to improve dynamic stability: A hybrid technique. Electrical Power and Energy Systems, 64, 429-438.

Lepuschitz, E. (2015). Geographic information systems in mountain risk and disaster management. Appl. Geogr. 63, 212-219.

Mohamadabadi, H., S., Tichkowsky, G., \& Kumar, A. (2009). Development of A Multicriteria Assesment Model for Ranking of Renewable and Non-Renewable Transportation Fuel Vehicles, Energy, 34, 112-125, (2009).

Mokhtarian, M. N. (2011). A new fuzzy weighted average (FWA) method based on left and right scores: An application for determining a suitable location for a gas oil station. Computers and Mathematics with Applications, 61, 3136-3145.

Mokhtarian, M. N., Nezhad, S. S. ve Makui, A. (2014). A new flexible and reliable interval valued fuzzy VIKOR method based on uncertainty risk reduction in decision making process: An application for determining a suitable location for digging some pits for municipal wet waste landfill. Computers \& Industrial Engineering, 78, 213-233.

Murad A. A. (2007). Creating a GIS application for health services at Jeddah city. Comput Bio Med;37:879-89.

Rahimi, F, Goli A. \& Rezaee, R. (2017). Hospital location-allocation in Shiraz using geo- graphical information system (GIS). Shiraz E-Med J;18(8):e57572. doi: 10. 5812/semj.57572.

Saaty, T. L. (1980). The Analytic Hierarchy Process. McGraw-Hill, New York.

Sipahi, S. \& Timor, M. (2010). The analytic hierarchy process and analytic network process: an overview of applications. Management Decision 48(5), 775-808. doi: 10.1108/00251741011043920.

Sharmin, N. \& Neema, M. N. (2013). A GIS-based multi-criteria analysis to site appropriate locations of hospitals in Dhaka City. Hospital (Rio J);8:0-37 .

Şenkayas, H. \& Hekimoğlu, H. (2013). Çok Kriterli Tedarikçi Seçim Problemine PROMETHEE Yöntemi Uygulaması. Verimlilik Dergisi(2).

Subramanian, N. \& Ramanathan, R., (2012). A review of applications of analytic hierarchy process in operations management. Economics 138 (2), 215e241.

Vahidnia, M. H., Alesheikh, A. A. \& Alimohammadi, A. (2009). Hospital site selection using fuzzy AHP and its derivatives. J Environ Manage; 90(10):3048-56 .

Velasquez, M. \& Hester, P. T. (2013). An analysis of multi-criteria decision making methods. Int J Oper Res;10(2):56-66.

Zhang, W., Cao, K., Liu, S. \& Huang, B., (2016). A multi-objective optimization approach for healthcare facility location-allocation problems in highly developed cities such as Hong Kong. Comput Environ Urban Syst;59:220-30 .

Wu, C. R., Lin, C. T. \& Chen, H. C. (2007). Optimal selection of location for Taiwanese hospitals to ensure a competitive advantage by using the analytic hierarchy process and sensitivity analysis. Build Environment; $42: 1431-44$.

Wu, C. R., Lin, C. T. \& Chen, H. C. (2009). Integrated environmental assessment of the location selection with fuzzy analytical network process. Qual Quant;43:351-80.

Yang, L., Ji, X., Gao, Z. ve Li, K. (2007). Logistics distribution centers location problem and algorithm under fuzzy environment. Journal of Computational and Applied Mathematics, 208, 303 - 315. 